\title{
Outcome of therapy-related myeloid neoplasms treated with azacitidine
}

\author{
Luana Fianchi ${ }^{1}$, Marianna Criscuolo ${ }^{1}$, Monia Lunghi ${ }^{2}$, Gianluca Gaidano ${ }^{2}$, Massimo Breccia ${ }^{3}$, Alessandro Levis ${ }^{4}$, \\ Carlo Finelli ${ }^{5}$, Valeria Santini ${ }^{6}$, Pellegrino Musto ${ }^{7}$, Esther N Oliva ${ }^{8}$, Pietro Leoni ${ }^{9}$, Antonietta Aloe Spiriti ${ }^{10}$, \\ Francesco D'Alò', Stefan Hohaus', Livio Pagano', Giuseppe Leone ${ }^{1}$ and Maria Teresa Voso ${ }^{1 *}$
}

\begin{abstract}
Background: Therapy-related myeloid neoplasms (t-MN), including myelodysplastic syndromes and acute myeloid leukemia (t-MDS and t-AML) are associated to clinical and biologic unfavorable prognostic features, including high levels of DNA methylation.

Methods: We retrospectively evaluated 50 t-MN patients (34 MDS and $16 \mathrm{AML}$ ) selected among all patients receiving azacitidine (AZA) at 10 Italian Hematology Centers. Patients had developed a t-MN at a median of 6.5 years (range 1.7- 29) after treatment of the primary tumor (hematological neoplasm, 27 patients; solid tumor, 23 patients).

Results: The overall response rate was 42\% (complete remission: 10 patients, partial remission: 2 and hematological improvement: 8 patients) and was obtained after a median of 3 cycles (range 1-6). Median overall survival (OS) was 21 months (range 1-53.6+) from AZA start. OS was significantly better in patients with less than 20\% blasts, in normal karyotype t-AML and when AZA was used as front-line treatment. This was confirmed by the multivariate analysis.

Conclusions: This study reports efficacy of AZA in the largest series of therapy-related MN patients treated with 5-AZA. Our data show that blasts and karyotype maintain their important prognostic role in t-MN also in the azacitidine era.
\end{abstract}

Keywords: Therapy related myeloid neoplasms, Hypomethylating agents

\section{Background}

Therapy-related myeloid neoplasms ( $\mathrm{t}-\mathrm{MN})$ have been recognized as a clinical and biological distinct entity in the 2008 WHO AML classification [1]. By definition, these diseases occur after cytotoxic treatment for a primary cancer or after immunosuppressive treatment. t-MN account for about $10 \%$ of all AML, and may arise from few months to several years after the primary tumor, depending on type of cytotoxic treatment, cumulative dose and dose-intensity [2,3]. At disease onset, t-MN typically present with unfavorable features, such as peripheral blood cytopenias, complex karyotype, and chromosome 11, 5 or 7 abnormalities [4-6].

\footnotetext{
* Correspondence: mtvoso@rm.unicatt.it

${ }^{1}$ Istituto di Ematologia, Università Cattolica del Sacro Cuore, 00168, Roma, Italy

Full list of author information is available at the end of the article
}

Increased rates of gene-specific hypermethylation have been reported in $\mathrm{t}-\mathrm{MN}$ [6-9].

Because performance status is often poor, mostly due to age, primary tumor and exposition to prior therapies, the use of standard chemotherapy protocols is generally impaired in these patients. Treatment varies from supportive care to conventional chemotherapy and allogeneic HSCT, but outcome remains dismal. Even in aggressively treated cases, complete remission rates are usually lower and remission duration is shorter than in de novo MDS/AML, with median survival rates of less than one year in most studies [5,10-13]. Allogeneic HSCT is the only curative option, but it is not feasible in the majority of patients and is often complicated by high transplantation-related mortality rates [10]. Response rates similar to de novo AML have been recently obtained only for t-AML patients carrying 
$\mathrm{t}(15 ; 17)$ or $\mathrm{t}(8 ; 21)$ translocations and included in standard protocols [5].

During the last few years, hypomethylating agents have been largely used in the treatment of intermediate- 2 and high risk MDS [14]. Azacitidine has been shown to be effective also in unfavorable patient sub-groups, inducing response rates up to $60 \%$ and improving survival compared to conventional care [14-16].

Here we report that azacitidine treatment might represent a safe and effective option in t-MN patients, given the biological and clinical characteristic of the disease and the potentially fatal consequences of more aggressive therapies.

\section{Methods}

\section{Patients and methods}

In this multicenter study, we retrospectively collected clinical data of patients diagnosed with $\mathrm{t}-\mathrm{MN}$ and treated with azacitidine (AZA, Vidaza ${ }^{\mathrm{TM}}$, Celgene Corp.) at 10 Italian Hematology Centers. Fifty cases of t-MN consecutively treated with AZA were identified and analyzed among all patients with MDS or AML receiving AZA at the participating centers between October 2005 and August 2011. Criteria for AZA treatment were: diagnosis of $\mathrm{t}-\mathrm{MN}$ according to the WHO classification, defined as leukemias occurring in patients with a history of prior cytotoxic treatment for a primary tumor. Further criteria were adequate renal and hepatic function, and absence of uncontrolled infections. Patients gave written informed consent to treatment and to the collection of clinical data, in accordance with the Declaration of Helsinki and institutional guidelines.

AZA was started at a median of 1.8 months (range 029) from t-MN diagnosis, at the conventional dose of $75 \mathrm{mg} / \mathrm{m}^{2}$ daily for 7 days (36 patients, $72 \%$ ), or at a fixed dose of $100 \mathrm{mg}$ daily for 5,7 or 10 days (3, 7 and 4 patients, respectively) every 4 weeks. A median of 4 cycles (range 1-23) were administered, with $37.7 \%$ of patients receiving 4 or more cycles.

AZA was administered until disease progression, unacceptable toxicity, or patient decision to withdraw consent. Response was assessed according to the modified International Working Group (IWG-2006) criteria $[17,18]$. We evaluated overall response (OR), including complete remission (CR), partial remission (PR) and hematological improvement (HI) rates, and overall survival.

Adverse events were graded according to the National Cancer Institute Common Toxicity Criteria (CTC-NCI, version 4.0).

\section{Statistical analysis}

Associations between patient characteristics were analyzed using the Fisher's exact test. Overall survival was calculated from start of AZA treatment to date of death from any cause or of the last follow-up. Survival curves were estimated using the Kaplan-Meier product limits method. Log-rank test was applied to study survival differences according to patient characteristics. Age $(\leq 65$ vs $>65$ y.o.), primary malignancy (hematological vs solid), comorbidity index (HCT-CI) (19), AZA dose (75 mg/ $\mathrm{m}^{2} / 7$ days vs $100 \mathrm{mg} /$ day 10 days vs $100 \mathrm{mg}$ /day 5 or 7 days), WHO diagnosis (RCMD vs RAEB $1 / 2$ vs AML), karyotype (normal vs abnormal), chromosome 7 abnormalities, transfusion dependence, previous treatment (no vs ESA vs hydroxyurea or chemotherapy) were evaluated in the univariate analysis. Cox proportional hazard model was also used for multivariate analysis of factors with prognostic significance in the univariate analysis (blast count $>20 \%$; karyotype, previous cytotoxic treatment for t-MDS/AML). Computations were performed using the Stata 10.0 software (Stata Corp., College Station, TX). All tests were two-sided with $\alpha=0.05$.

\section{Results}

\section{Patient characteristics}

The main patient characteristics at diagnosis are reported in Table 1. There were 28 males and 22 females, with a median age of 66 years (range 37-84). According to the WHO classification, there were 34 MDS (12 RCMD, 9 RAEB1 and 13 RAEB2) and 16 AML.

All patients had previously received chemotherapy (27 patients, $52 \%$ ), radiotherapy ( 9 patients, $17 \%$ ) or a combination of both (14 patients, 27\%) for their primary malignancy.

The primary malignancy was a hematological neoplasm in 27 cases (54\%), and a solid tumor in 23 cases (46\%). t-MN occurred at a median of 6.1 years (range 0.2 - 29.8 years) from treatment of the primary malignancy (Table 1).

Karyotype was evaluable in 47 patients and was normal in 17 (34\%), complex (3 or more aberrations) in 20 $(43 \%)$, and with a single chromosome abnormality in 10 cases (20\%). Deletion or monosomy of chromosome 7 was present as single alteration or in the context of a complex karyotype in 14 patients (30\%).

Twenty-six patients (52\%) were transfusion-dependent before AZA start [median 2 units of red blood cells (range 1-10) /month and median 5 units of platelets /month (range 1-12)]. Four patients had previously received erythropoietin, and 6 patients had previously been treated with hydroxyurea or standard AML induction therapy, while in 40 patients AZA was used as front-line treatment.

\section{Treatment response and overall survival}

Treatment response was evaluated in 48 patients (35 MDS and 13 AML) after a median of 3 cycles of AZA 
Table 1 Clinical characteristics of 50 patients with t-MN treated with azacitidine

\begin{tabular}{ll}
\hline Patient Characteristics & \multicolumn{1}{c}{$\boldsymbol{n}$ (range) } \\
\hline Median age (years, median, range) & $66(37-84)$ \\
\hline Sex (M/F) & $28 / 22$ \\
\hline ECOG PS & 46 \\
\hline $0-1$ & 4 \\
\hline 2-3 & \\
\hline Type of t-MDS/AML according to the WHO & 16 \\
\hline - AML: & 5 \\
\hline BM-blasts 20-29\% & 11 \\
\hline BM-blasts $\geq 30 \%$ & 34 \\
\hline - MDS: & 12 \\
\hline RCMD & 9 \\
\hline RAEB1 & 13 \\
\hline RAEB 2
\end{tabular}

Primary malignancy :

\begin{tabular}{ll}
\hline - Lymphoproliferative disease & 19 \\
\hline - Multiple myeloma & 3 \\
\hline - Chronic myeloproliferative disease & 5 \\
\hline - Breast cancer & 6 \\
\hline - Urogenital & 9 \\
\hline - Other & 8
\end{tabular}

\section{Treatment for Primary Malignancy:}

\begin{tabular}{ll}
\hline - Chemotherapy & 27 \\
\hline - Radiotherapy & 9 \\
\hline - RTx + CTx & 14 \\
\hline Median latency between primary cytotoxic & $6.1(0.2-29.8)$
\end{tabular}

therapy and t-MN diagnosis (years)

\begin{tabular}{ll}
\hline Median value at diagnosis (range): & \\
\hline - White blood cell counts $\left(10^{9} / \mathrm{L}\right)$ & $2.6(0.1-26)$ \\
\hline - Platelets $\left(10^{9} / \mathrm{L}\right)$ & $69.5(5-395)$ \\
\hline - Bone Marrow blasts (\%) & $13(1-90)$ \\
\hline - LDH $(\mathrm{UI} / \mathrm{L})$ & $403(130-2498)$ \\
\hline Median interval between t-MN diagnosis & $1.8(0-39)$ \\
and AZA treatment (months) & \\
\hline Response to treatment: & $20(42 \%)$ \\
\hline - Overall response: & $10(21 \%)$ \\
\hline - CR & $2(4.2 \%)$ \\
\hline - PR & $8(16.7 \%)$ \\
\hline - HI & $15(31 \%)$ \\
\hline - Stable disease & $13(27 \%)$ \\
\hline - Progression & 2 \\
\hline - Not evaluable & $3($ range 1-6) \\
\hline Median cycles number for response
\end{tabular}

Legend: $R T x$ : Radiotherapy ; CTx: Chemotherapy; $C R$ : complete remission; $P R$ : partial remission; $\mathrm{HI}$ : hematological improvement. (range 1-6). Two patients received only 1 cycle and interrupted treatment on patient's request (1 patients with stable disease) and due to severe constipation (1 patient). (Table 1). The overall response rate (ORR) was $42 \%$, with complete remission in 10 patients (21\%), partial remission in $2(4.2 \%)$ and hematological improvement in 8 patients (16.7\%). The disease was stable in 15 patients (31\%), while 13 patients (27\%) presented disease progression at a median of 4 AZA cycles (range 3-7). Treatment was generally well tolerated. Sixteen patients (32\%) experienced grade 3 or 4 myelosuppression including neutropenia (8 patients), thrombocytopenia and neutropenia (7 patients) or anemia (1 patient). Eight patients (16\%) developed an infection (pneumonia in 7 patients and sepsis in 1), that was the cause of death in 2 cases (4\%). Other grade 3 or 4 non hematological adverse events consisted of erythema at the injection site in 2 cases and constipation in 2 cases.

Median duration of response was 7 months (range 3$47+$ ). Five patients (10\%), 4 resistant to AZA, underwent allogeneic stem cell transplantation following azacitidine.

Notably, 5 patients $(10 \%)$ presented a relapse of the primary malignancy (1 non-Hodgkin lymphoma, 2 breast cancers, 1 bladder cancer and 1 cancer of the uterus) after a median of 4 cycles of AZA (range 210 ), and at a median of 13 years from the diagnosis of the primary malignancy (range 9-26 years). None of the patients died as a consequence of these relapses, but they were resistant to AZA and died due to $\mathrm{t}-\mathrm{MN}$ progression.

Median overall survival of t-MN patients was 25.6 months (range 1.1-61.1+) from diagnosis and 21 months (range 1-53.6+) from azacitidine start (Figure 1). Survival was $72 \%$ (95 C.I.: $53-82 \%$ ) at the median follow up of 8.7 months (range 1-54).

By stratifying patients according to t-MN type (below or over $20 \%$ bone marrow blasts), the overall response rate appeared to be higher in t-MDS versus t-AML, albeit the difference was not statistically significant $(50 \%$ vs $21 \%, p=0.1)$. Overall survival from initial $t-M N$ diagnosis or from AZA start was significantly better in t-MDS versus t-AML (40.4 months versus 19.4 months from initial diagnosis, p: 0.005 , and 30.9 months versus 8.5 months, from AZA start, p: 0.0045, Figure 2). This significant difference in overall survival was confirmed also when stratifying patients according to WHO categories (RCMD versus RAEB1-2 versus AML, $\mathrm{p}=0.02$ ) (Figure 3).

Concerning significant prognostic factors for survival, aberrant karyotype confirmed its negative value in t-AML (median survival: 8.3 vs 17 months in normal karyotype, $\mathrm{p}=0.045$ ), but not in $\mathrm{t}-\mathrm{MDS}$ (median survival: 21.9 vs 42.3 months, $\mathrm{p}=0.57$, Figure 3 ). Survival was superior in patients who received AZA as front-line 


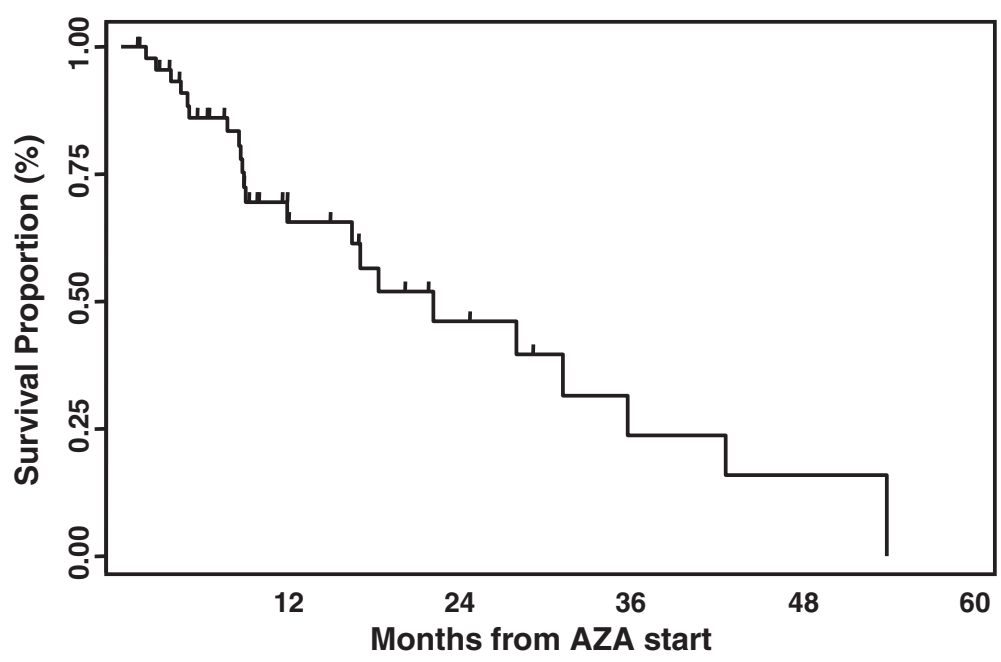

Figure 1 Overall survival of $\mathbf{5 0}$ t-MN patients treated with azacitidine. Median survival was 25.6 months (range 1.1-61.1+) from initial diagnosis and 21 months (range 1-53.6+) from AZA start.

treatment, compared to patients who received other cytotoxic drugs to treat $\mathrm{t}-\mathrm{MN}$ prior to AZA $(\mathrm{p}=0.0001$, Table 2). No survival differences were observed when stratifying patients according to the type of previous

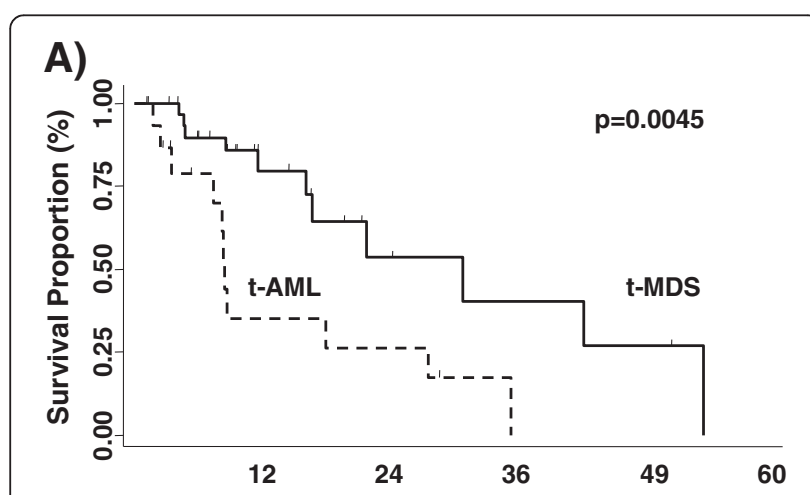

B)

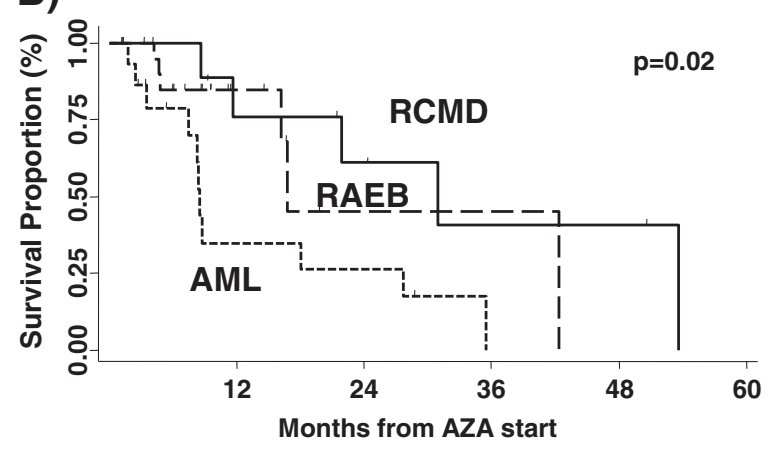

Figure $2 \mathrm{t}$-AML patients had a significantly worse survival than t-MDS patients. A) Median survival was 8.5 months in t-AML versus 30.9 months in t-MDS $(p=0.0045)$, classified according to the WHO classification (over 20\% bone marrow blasts as definition for AML) B) In t-MDS, there were no survival differences when stratifying for WHO subtypes (RCMD vs RAEB1-2). malignancy, time between treatment of the primary malignancy and development of $\mathrm{t}-\mathrm{MN}$, time between $\mathrm{t}-\mathrm{MN}$ diagnosis and AZA start, comorbidity index (HCT-CI) [19] peripheral blood counts, IPSS score in MDS,

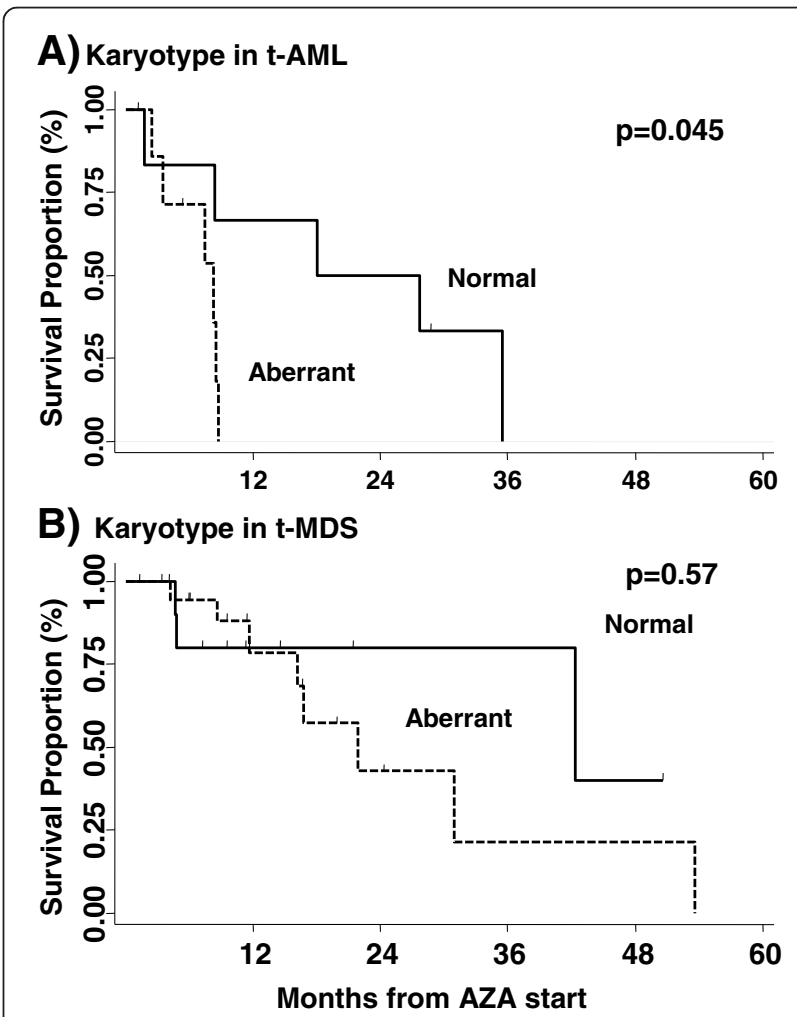

Figure 3 Aberrant karyotype was predictor of death in t-AML, but not in t-MDS patients. Survival was studied according to the presence of any cytogenetic aberrations versus normal karyotype. 
Table 2 Prognostic factors for overall survival

\begin{tabular}{|c|c|c|c|c|}
\hline & $\begin{array}{l}\text { Patients } \\
\text { (n) }\end{array}$ & $\begin{array}{l}\text { Number of } \\
\text { responders }\end{array}$ & $\begin{array}{l}\text { Median OS } \\
\text { (months) }\end{array}$ & $p$ \\
\hline \multicolumn{5}{|l|}{ Age } \\
\hline$\leq 65$ years & 24 & 10 & 21.9 & 0.85 \\
\hline$>65$ years & 26 & 10 & 24.5 & \\
\hline \multicolumn{5}{|l|}{ Primary Malignancy } \\
\hline Hematological & 27 & 12 & 11.67 & 0.83 \\
\hline Solid & 23 & 8 & 17.97 & \\
\hline \multicolumn{5}{|l|}{ azacitidine dose } \\
\hline $75 \mathrm{mg} / \mathrm{smq} / 7$ days & 36 & 12 & 16.7 & 0.31 \\
\hline 100 mg/day 10 days & 4 & 3 & 14.2 & \\
\hline 100 mg/day 5 or 7 days & 10 & 5 & 16.2 & \\
\hline \multicolumn{5}{|l|}{ WHO diagnosis } \\
\hline $\mathrm{RCMD}$ & 12 & 9 & 30.9 & \\
\hline RAEB $1 / 2$ & 22 & 7 & 16.8 & 0.02 \\
\hline AML & 16 & 4 & 8.5 & \\
\hline \multicolumn{5}{|l|}{ Karyotype } \\
\hline Normal & 8 & 8 & 27.7 & \\
\hline Single or double abnormality & 9 & 3 & 11.6 & $0.66^{*}$ \\
\hline Complex & 20 & 9 & 16.2 & \\
\hline
\end{tabular}

\begin{tabular}{lllll}
\hline \multicolumn{2}{l}{ Chromosome 7 abnormalities } & & & \\
\hline Yes & 14 & 8 & 11.63 & 0.72 \\
\hline No & 33 & 12 & 17.96 & \\
\hline Transfusion dependence & & & & \\
\hline Yes & 26 & 10 & 11.6 & 0.38 \\
\hline No & 24 & 10 & 21.9 & \\
\hline
\end{tabular}

Previous Treatment

\begin{tabular}{lllll}
\hline No pre-treatment & 40 & 17 & 27.7 & $\mathbf{0 . 0 0 0 1}$ \\
\hline ESA & 4 & 2 & 16.2 & \\
\hline Hydroxyurea & 2 & 1 & 9.5 & \\
\hline Conventional Chemotherapy & 4 & 0 & 5.4 &
\end{tabular}

\begin{tabular}{lll}
\hline $\mathrm{HCT}-\mathrm{Cl}$ & \\
\hline $0-2$ & 5 & 0
\end{tabular}

\begin{tabular}{lllll}
\hline $0-2$ & 5 & 0 & 8.8 & \\
\hline 3 & 19 & 6 & 8.5 & 0.2 \\
\hline 4 & 6 & 4 & 53.7 & \\
\hline$>5$ & 9 & 4 & 16.2 &
\end{tabular}

* The difference in overall survival between normal and aberrant karyotype was however statistically significant restricting the analysis to t-AML patients (Figure 3A).

${ }^{\S}$ Number of patients achieving $\mathrm{CR}, \mathrm{PR}$ or $\mathrm{HI} ;{ }^{\#} \mathrm{HCT}-\mathrm{Cl}$ data were available for 39 patients.

transfusion-dependence or AZA dose (Table 2). The multivariate analysis confirmed the significant negative prognostic value of bone marrow blast over $20 \%$, and karyotype (Table 3 ).

\section{Discussion}

Prognosis of patients with therapy-related myeloid neoplasms treated with conventional chemotherapy is poor, with lower remission rates and shorter remission duration than in de novo AML. Furthermore, t-MN display high levels of DNA methylation [6-9] and high frequency of monosomal karyotype, including complete or partial deletions of chromosome 5 or $7[5,10,20]$.

The biological features and the unsatisfactory results of standard chemotherapy provided the rationale for our retrospective study on the role of azacitidine in t-MN. We observed $42 \%$ overall response rate and a median overall survival of 21 months. The outcome of our AZA-treated t-MN patients is similar to results obtained in de novo high-risk MDS treated with AZA at standard doses $[14,21]$ and also favorably compares to conventional therapy in $\mathrm{t}-\mathrm{MN}[10,12]$. In a recently published study by Kayser et al.. on 200 selected t-AML patients included in 6 prospective German-Austrian multi-center trials, complete response to standard induction therapy was $63 \%$ in $\mathrm{t}$-AML, with a median overall survival of about 15 months [5]. There are only few data on AZA efficacy in $\mathrm{t}-\mathrm{MN}$. Seventy-four t-MDS were included in a large cohort of 282 high-risk MDS treated with AZA [15]. ORR was $43 \%$ for the whole patient cohort, but therapy-related forms had a shorter survival (median 9.2 months versus 15.3 months in de novo MDS, $\mathrm{p}=0.002)[15]$.

In our study, AZA efficacy was particularly evident in t-MDS, who had a significantly better overall survival than t-AML patients. This was true also considering WHO subgroups, with significantly different overall survival in refractory cytopenia with multilineage dysplasia (RCMD), versus RAEB- 1 and -2 , versus AML. These data, confirm the role of WHO subgroups in therapyrelated as in de novo-MDS [22,23].

Although karyotype maintains its prognostic value in $\mathrm{t}$-AML, survival of $\mathrm{t}$-AML patients within the same cytogenetic risk group is generally shorter than that of patients with de novo AML [24]. Karyotype prognostic groups differ between MDS and AML. Due to the limited number of patients, especially those with a favorable karyotype, we grouped patients according to the type of $\mathrm{t}-\mathrm{MN}$ and presence of any chromosomal abnormalities. As a result, our t-AML patients with aberrant karyotype (including chromosome 7 alterations in 30\% of cases) had a significantly shorter survival than patients with a normal karyotype. Also, patients treated with AZA front-line had a significantly better outcome than patients who received previous cytotoxic drugs to treat

Table 3 Multivariate analysis for overall survival

\begin{tabular}{llll}
\hline & Hazard Ratio & $\mathbf{p}$ & $\mathbf{9 5 \%}$ C.I. \\
\hline WHO type (t-AML vs t-MDS) & 3.49 & 0.03 & $1.17-10.46$ \\
\hline Karyotype (aberrant versus normal) & 2.2 & 0.015 & $0.75-6.58$ \\
\hline Front-line AZA (no vs yes) & 3.45 & 0.08 & $0.87-13.62$ \\
\hline
\end{tabular}


$\mathrm{t}-\mathrm{MN}$. In the same line, normal karyotype, bone marrow blast counts below $15 \%$ and no previous treatment with low-dose cytosine-arabinoside independently predicted better response to AZA in higher risk MDS [15]. It is also possible that patients treated with cytoreductive chemotherapy had a more aggressive t-MN disease, and thus were less likely to respond to azacitidine when used in second line.

In our series 5 patients had a chronic myeloproliferative disease as previous neoplasm. The inclusion of these disorders into the list of primary malignancies is debated due to possibility that the AML transformation might represent a natural evolution of disease. The exposure to cytotoxic agents however could hasten or induce this transformation as also suggested by an increased risk of AML in patients who were treated with radioactive phosphorus or chlorambucil in the Polycytemia Vera Study Group trial [25].

Five of fifty patients had a relapse of the previous malignancy during treatment with AZA after a median of 4 cycles, and at a median of 13 years from the diagnosis of the primary malignancy. This observation should be at least a warning to include re-evaluation and monitoring of disease activity of the primary malignancy in future studies on $\mathrm{t}-\mathrm{MN}$ treatment. There are only very limited data in the literature. More than 20 years ago, Carr et al. reported a higher incidence of testicular tumors after prolonged treatment with AZA in a rat model with an already high spontaneous tumor rate [26]. Itzykson et al did not report any relapse of the primary tumor in 74. $\mathrm{t}$-MDS patients treated with a median of six AZA cycles [15]. On the other hand, AZA efficacy has been reported in solid tumors and lymphoproliferative diseases $[27,28]$. Our group has recently reported a patient with Hodgkin lymphoma and a t-MDS, who achieved complete response of MDS and HL following AZA treatment [29].

In conclusion, our data indicate effectiveness of upfront AZA in $\mathrm{t}-\mathrm{MN}$, and are particularly encouraging in the setting of t-MDS. Blasts and karyotype maintain their important prognostic role for t-MN also in the azacitidine era. As there is no accepted standard treatment for patients with $\mathrm{t}-\mathrm{MN}$, other treatment approaches in the same time period of our study varied from supportive care only to low-dose cytarabine, gemtuzumabozogamicin in combination with G-CSF and cytarabine, standard induction chemotherapy and front-line allogeneic bone marrow transplantation [30]. Only about 25\% of $\mathrm{t}-\mathrm{MN}$ patients registered in 4 of the participating centers were treated with azacitidine. These data will help to design prospective studies for t-MN to address efficacy and risks of AZA treatment, in particular as a less toxic "bridging" therapy to a curative treatment approach as allogeneic transplantation.

\section{Competing interests}

The following authors declared a conflict of interest with Celgene: Honoraria: C.F., A.A.S., G.L., M.T.V.; Consultancy: A.L., E.O., P.M.

\section{Authors' contribution}

LF collected and analyzed patients' data, and wrote the manuscript. MC collected and analyzed patients' data.

ML collected and analyzed patients' data.

GG collected and analyzed patients' data, and revised the manuscript. MB collected and analyzed patients' data, and revised the manuscript. AL collected and analyzed patients' data, and revised the manuscript. CF collected and analyzed patients' data, and revised the manuscript. VS collected and analyzed patients' data, and revised the manuscript. PM collected and analyzed patients' data, and revised the manuscript. ENO collected and analyzed patients' data.

PL collected and analyzed patients' data.

AAS collected and analyzed patients' data.

FD collected and analyzed patients' data.

SH collected and analyzed patients' data, and revised the manuscript. LP collected and analyzed patients' data.

GL collected and analyzed patients' data, and revised the manuscript. MTV analyzed patients' data, and wrote the manuscript. All authors read and approved the final manuscript.

\section{Acknowledgements}

This work was supported by grants from Associazione Italiana Ricerca sul Cancro (A.I.R.C.) and FIRB (RBAP11TF7Z).

\section{Author details}

${ }^{1}$ Istituto di Ematologia, Università Cattolica del Sacro Cuore, 00168, Roma, Italy. ${ }^{2}$ Ematologia, Dipartimento di Medicina Traslazionale, Università del Piemonte Orientale Amedeo Avogadro, Novara, Italy. ${ }^{3}$ Ematologia, Università La Sapienza, Roma, Italy. ${ }^{4}$ Ospedale di Alessandria, Alessandria, Italy.

${ }^{5}$ Universita' di Bologna, Bologna, Italy. ${ }^{6}$ Ematologia Firenze, Firenze, Italy.

${ }^{7}$ Dipartimento Onco-Ematologico, IRCCS, Centro di Riferimento Oncologico della Basilicata, Rionero in Vulture, Italy. ${ }^{8}$ Azienda Ospedaliera BianchiMelacrino-Morelli, Reggio Calabria, Italy. ' ${ }^{9}$ matologia Ancona, Ancona, Italy. ${ }^{10}$ Ospedale Sant'Andrea, Roma, Italy.

Received: 24 May 2012 Accepted: 19 July 2012

Published: 1 August 2012

\section{References}

1. Vardiman JW, Thiele J, Arber DA, Brunning RD, Borowitz MJ, Porwit A, Harris NL, Le Beau MM, Hellström-Lindberg E, Tefferi A, Bloomfield CD: The 2008 revision of the World Health Organization (WHO) classification of myeloid neoplasms and acute leukemia: rationale and important changes. Blood 2008, 114:937-951.

2. Leone G, Fianchi L, Voso MT: Therapy-related myeloid neoplasms. Curr Opin Oncol 2011, 23:672-680.

3. Mauritzson N, Albin M, Rylander L, Billström R, Ahlgren T, Mikoczy Z, Björk J, Strömberg U, Nilsson PG, Mitelman F, Hagmar L, Johansson B: Pooled analysis of clinical and cytogenetic features in treatment-related and de novo adult acute myeloid leukemia and myelodysplastic syndromes based on a consecutive series of 761 patients analyzed 1976-1993 and on 5098 unselected cases reported in the literature 1974-2001. Leukemia 2002, 16:2366-2378.

4. Stoddart A, McNerney ME, Bartom E, Bergerson R, Young DJ, Qian Z, Wang J, Fernald AA, Davis EM, Larson RA, White KP, Le Beau MM: Genetic pathways leading to therapy-related myeloid neoplasms. Mediterr J Hematol Infect Dis. 2011, 3:e2011019.

5. Kayser S, Döhner K, Krauter J, Köhne CH, Horst HA, Held G, von LilienfeldToal M, Wilhelm S, Kündgen A, Götze K, Rummel M, Nachbaur D, Schlegelberger B, Göhring G, Späth D, Morlok C, Zucknick M, Ganser A, Döhner H, Schlenk RF: The impact of therapy-related acute myeloid leukemia (AML) on outcome in 2853 adult patients with newly diagnosed AML. Blood 2011, 117:2137-2145.

6. Christiansen DH, Andersen MK, Pedersen-Bjergaard J: Methylation of p15INK4B is common, is associated with deletion of genes on chromosome arm $7 q$ and predicts a poor prognosis in therapy-related 
myelodysplasia and acute myeloid leukemia. Leukemia 2003, 17:1813-1819.

7. Greco M, D'Alò F, Scardocci A, Criscuolo M, Fabiani E, Guidi F, Di Ruscio A, Migliara G, Pagano L, Fianchi L, Chiusolo P, Hohaus S, Leone G, Voso MT: Promoter methylation of DAPK1, E-cadherin and thrombospondin-1 in de novo and therapy-related myeloid neoplasms. Blood Cells Mol Dis 2010, 45:181-185.

8. Scardocci A, Guidi F, D'Alo' F, Gumiero D, Fabiani E, Di Ruscio A, Martini M, Larocca LM, Zollino M, Hohaus S, Leone G, Voso MT: Reduced BRCA1 expression due to promoter hypermethylation in therapy-related acute myeloid leukaemia. Br J Cancer 2006, 95:1108-1113.

9. Voso MT, D'Alò F, Greco M, Fabiani E, Criscuolo M, Migliara G, Pagano L, Fianchi L, Guidi F, Hohaus S, Leone G: Epigenetic changes in therapyrelated MDS/AML. Chem Biol Interact 2010, 84:46-49.

10. Smith SM, Le Beau MM, Huo D, Karrison T, Sobecks RM, Anastasi J, Vardiman JW, Rowley JD, Larson RA: Clinical-cytogenetic associations in 306 patients with therapy-related myelodysplasia and myeloid leukemia: the University of Chicago series. Blood 2003, 102:43-52.

11. Chang C, Storer BE, Scott BL, Bryant EM, Shulman HM, Flowers ME, Sandmaier BM, Witherspoon RP, Nash RA, Sanders JE, Bedalov A, Hansen JA, Clurman BE, Storb R, Appelbaum FR, Deeg HJ: Hematopoietic cell transplantation in patients with myelodysplastic syndrome or acute myeloid leukemia arising from myelodysplastic syndrome: Similar outcomes in patients with de novo disease and disease following prior therapy or antecedent hematologic disorders. Blood 2007, 110:1379-1387.

12. Larson RA, Le Beau MM: Prognosis and therapy when acute promyelocytic leukemia and other "good risk" acute myeloid leukemias occur as a therapy-related myeloid neoplasm. Mediterr J Hematol Infect Dis. 2011, 3:e2011032.

13. Grimwade D, Walker H, Harrison G, Oliver F, Chatters S, Harrison CJ, Wheatley K, Burnett AK, Goldstone AH: The predictive value of hierarchical cytogenetic classification in older adults with acute myeloid leukemia (AML): analysis of 1065 patients entered into the United Kingdom Medical Research Council AML11 trial. Blood 2001, 98:1312-1320.

14. Fenaux P, Mufti GJ, Hellstrom-Lindberg E, Santini V, Finelli C, Giagounidis A, Schoch R, Gattermann N, Sanz G, List A, Gore SD, Seymour JF, Bennett JM, Byrd J, Backstrom J, Zimmerman L, McKenzie D, Beach C, Silverman LR: Efficacy of azacitidine compared with that of conventional care regimens in the treatment of higher-risk myelodysplastic syndromes: a randomised, open-label, phase III study. Lancet Oncol 2009, 10:223-232.

15. Itzykson R, Thépot S, Quesnel B, Dreyfus F, Beyne-Rauzy O, Turlure P, Vey N, Recher C, Dartigeas C, Legros L, Delaunay J, Salanoubat C, Visanica S, Stamatoullas A, Isnard F, Marfaing-Koka A, de Botton S, Chelghoum Y, Taksin AL, Plantier I, Ame S, Boehrer S, Gardin C, Beach CL, Adès L, Fenaux P: Prognostic factors for response and overall survival in 282 patients with higher-risk myelodysplastic syndromes treated with azacitidine. Blood 2011, 117:403-411.

16. Raj K, John A, Ho A, Chronis C, Khan S, Samuel J, Pomplun S, Thomas NS, Mufti GJ: CDKN2B methylation status and isolated chromosome 7 abnormalities predict responses to treatment with azacitidine. Leukemia 2007, 21:1937-1944

17. Cheson BD, Bennett JM, Kopecky KJ, Büchner T, Willman CL, Estey EH, Schiffer CA, Doehner H, Tallman MS, Lister TA, Lo-Coco F, Willemze R, Biondi A, Hiddemann W, Larson RA, Löwenberg B, Sanz MA, Head DR, Ohno R, Bloomfield CD: Revised recommendations of the International Working Group for diagnosis, standardization of response criteria, treatment outcomes, and reporting standards for therapeutic trials in acute myeloid leukemia. J Clin Oncol 2003, 21:4642-4649.

18. Cheson BD, Greenberg PL, Bennett JM, Lowenberg B, Wijermans PW, Nimer SD, Pinto A, Beran M, de Witte TM, Stone RM, Mittelman M, Sanz GF, Gore SD, Schiffer CA, Kantarjian H: Clinical application and proposal for modification of the International Working Group (IWG) response criteria in myelodysplasia. Blood 2006, 108:419-425.

19. Sorror ML, Maris MB, Storb R, Baron F, Sandmaier BM, Maloney DG, Storer B: Hematopoietic cell transplantation (HCT)-specific comorbidity index: a new tool for risk assessment before allogeneic HCT. Blood 2005, 106:2912-2919.

20. D'Alò F, Fianchi L, Fabiani E, Criscuolo M, Greco M, Guidi F, Pagano L, Leone G, Voso MT: Similarities and differences between therapy-related and elderly acute myeloid leukemia. Mediterr J Hematol Infect Dis 2011, 3:e2011052.
21. Fenaux P, Mufti GJ, Hellstrom-Lindberg E, Santini V, Gattermann N, Germing U, Sanz G, List AF, Gore S, Seymour JF, Dombret H, Backstrom J,

Zimmerman L, McKenzie D, Beach CL, Silverman LR: Azacitidine prolongs overall survival compared with conventional care regimens in elderly patients with low bone marrow blast count acute myeloid leukemia. J Clin Oncol 2010, 28:562-569.

22. Malcovati L, Della Porta MG, Pascutto C, Invernizzi R, Boni M, Travaglino E, Passamonti F, Arcaini L, Maffioli M, Bernasconi P, Lazzarino M, Cazzola M: Prognostic factors and life expectancy in myelodysplastic syndromes classified according to WHO criteria: a basis for clinical decision making. J Clin Oncol 2005, 23:7594-7603.

23. Howe RB, Porwit-MacDonald A, Wanat R, Tehranchi R, Hellström-Lindberg E: The WHO Classification of MDS does make a difference. Blood 2004, 103:3265-3270.

24. Kern W, Haferlach T, Schnittger S, Hiddemann W, Schoch C: Prognosis in therapy related acute myeloid leukemia and impact of karyotype. J Clin Oncol 2004, 22:2510-2511.

25. Murphy S: Therapeutic dilemmas: balancing the risks of bleeding, thrombosis, and leukemic transformation in myeloproliferative disorders (MPD). Thromb Haemost 1997, 78:622-626.

26. Carr Bl, Rahbar S, Asmeron Y, Riggs A, Winberg CD: Carcinogenicity and haemoglobin synthesis induction by cytidine analogues. Br J Cancer 1988, 857:395-402.

27. Stathis A, Hotte SJ, Chen EX, Hirte HW, Hirte HW, Oza AM, Moretto P, Webster S, Laughlin A, Stayner LA, McGill S, Wang L, Zhang WJ, EspinozaDelgado I, Holleran JL, Egorin MJ, Siu LL: Phase I study of decitabine in combination with vorinostat in patients with advanced solid tumors and non-Hodgkin's lymphomas. Clin Cancer Res 2011, 17:1582-1590.

28. Boumber $Y$, Issa JP: Epigenetics in cancer: what's the future? Oncology 2011, 25:220-226. 228

29. D'Alò F, Leone G, Hohaus S, Teofili L, Bozzoli V, Tisi MC, Rufini V, Calcagni $M L$, Voso MT: Response to azacitidine in a patient with relapsed Hodgkin Lymphoma and a therapy-related myelodysplastic syndrome. $\mathrm{Br}$ J Haematol 2011, 154:141-143

30. Fianchi L, Pagano L, Leoni F, Storti S, Voso MT, Valentini CG, Rutella S, Scardocci A, Caira M, Gianfaldoni G, Leone G: Gemtuzumab ozogamicin, cytosine arabinoside, G-CSF combination (G-AraMy) in the treatment of elderly patients with poor-prognosis acute myeloid leukemia. Ann Oncol 2008, 19:128-134.

doi:10.1186/1756-8722-5-44

Cite this article as: Fianchi et al:: Outcome of therapy-related myeloid neoplasms treated with azacitidine. Journal of Hematology \& Oncology 2012 5:44.

\section{Submit your next manuscript to BioMed Central and take full advantage of:}

- Convenient online submission

- Thorough peer review

- No space constraints or color figure charges

- Immediate publication on acceptance

- Inclusion in PubMed, CAS, Scopus and Google Scholar

- Research which is freely available for redistribution
C Biomed Central 